\title{
GRAPE SEED EXTRACT AND DENTIN REMINERALIZATION
}

\author{
Asmaa Aly Yassen* and Rehab Khalil Safy**
}

\begin{abstract}
Objective: The motivation of this study was to investigate the effect of grape seed extract on dentin remineralization.

Methodology: Sound dentin disks were prepared from the buccal surfaces of human impacted third molars. The specimens were stored in demineralizing solution for 72 hours at room temperature to create artificial carious lesions. They were divided into four groups according to the treatment used; 15\% GSE, 1000 ppm sodium fluoride, artificial saliva meanwhile teeth in the fourth group were kept without treatment as a negative control group. An in vitro $\mathrm{pH}$ cycling model for eight successive days was done. Subsequently micro-hardness of the specimens and their micromorphological appearance were evaluated using micro-indenter and Environmental scanning electron microscope (ESEM) respectively. Data were statically analyzed.
\end{abstract}

Results: The results indicated that there was a significant increase in dentin micro-hardness values of GSE and NaF groups in comparison to the demineralized and artificial saliva groups. The ESEM micrographs confirmed the micro-hardness results.

Conclusions: GSE is a promising natural remineralizing agent for treatment of the demineralized dentin.

KEY WORDS: Dentine, Demineralization, Remineralization, Grape seed

\section{INTRODUCTION}

Dentin constitutes the main bulk of the human tooth ${ }^{(1)}$. It carries the vitality and hydration to the whole tooth. Albeit, it is typically covered by overlying enamel and cementum and it can be exposed following their loss or gingival recession ${ }^{(2)}$. Once uncovered, dentin is negatively affected by the fluctuation in the oral environmental conditions through the demineralization and remineralization processes ${ }^{(3)}$. Its demineralization occurs much faster than the enamel as it is less mineralized and contains higher organic portion. Dentin Remineralization is the process in which regaining of the lost minerals and repairing of the damaged collagenous and non-collagenous proteins are included ${ }^{(4)}$. Various reviews bolster the idea that dentin

* Associate Professor of Restorative Dentistry, Cairo University and British University in Egypt

** Lecturer of Operative Dentistry, Suez Canal University 
remineralization happens through the development of leftover crystals inside the demineralized structures ${ }^{(4-8)}$. Others enrolled the role of the non-collagenous proteins which stick to the collagen matrix and play their roles through both inhibitory and accelerating capacities ${ }^{(9,10)}$.Improving dentin remineralization solves the problems of dentinal hypersensitivity, cervical wear and root caries ${ }^{(4)}$.The most commonly used remineralizing agent is the fluoride. However, there are reported constraints regarding its use as a traditional remineralizing agent. This is because of the risk of overexposure and rise of fluoride-resistant Streptococcus Mutans strains. These side effects have limited its utilization as a perfect therapeutic agent. Therefore, an extraordinary measure of dentin demineralization management has centered on looking for replacing treatment options which are, natural, effective and non-fluoride based ${ }^{(11,12)}$. Back to nature and searching for a natural biocompatible remineralizing agent, directed us towards the use of grape seed extract. It has an active ingredient which is the Proanthocyanidins (PA). This agent has antioxidant and anti-inflammatory properties. It has been accounted to fortify collagen-based tissues by increasing collagen crosslinks. There is a confirmation that PA increases collagen synthesis during development and quickens the transformation of soluble collagen to insoluble collagen ${ }^{(13)}$. The target of this study was to investigate the remineralizing impact of a PA-rich GSE on the demineralized dentine utilizing an in vitro $\mathrm{pH}$ cycling model. The null hypothesis established for this study was that there was no difference between the GSE, sodium fluoride and artificial saliva on the remineralization of the demineralized dentin.

\section{MATERIALS AND METHODS}

\section{Specimen preparation}

Ten human impacted third molars freshly extracted from patients in the age range 20-30 years were gathered, cleaned and put away in distilled water containing $0.2 \%$ thymol antiseptic solution for one month at $4{ }^{\circ} \mathrm{C}$ till testing ${ }^{(14)}$. Only intact teeth without having any enamel defects were incorporated. The utilization of extracted human teeth was confirmed by the Research Ethics Committee of the Faculty of dentistry, Suez Canal University, Egypt. Enamel was thoroughly removed from the coronal portion. Two guiding grooves were prepared on the mesial and distal surfaces utilizing cylindrical flat ended diamond stone ((ISO \#111/012), Mani inc. Japan) mounted on high handpiece with overflowing air-water spray then the two surfaces were ground flat. During enamel, removal color was used as a criterion to differentiate enamel from dentin. With the utilization of lead black pencil, a line was drawn on the proximal surfaces parallel to the DEJ yet underneath it by $0.5 \mathrm{~mm}$. The lines on the proximal surfaces were then connected painstakingly through the buccal surface at the DEJ level. The enamel tooth structure above the line was removed, and the buccal surface was ground flat to uncover dentin level utilizing a micro saw under running water. Forty dentin specimens with measurements of $3.0 \mathrm{~mm} \times 3.0 \mathrm{~mm} \times 2.0 \mathrm{~mm}$ were set up from the buccal and lingual surfaces of the selected teeth (4 from each molar) with a watercooled slow speed Isomet diamond saw. Dentin specimens from each tooth were ultra-sonicated in a deionized water bath (Unique, Ultrasonic Cleaner, Indaiatuba, SP, Brazil) to expel any debris. All dentin specimens were investigated under a reflected light microscope and discovered free of any imperfections, like cracks or pores. They were inserted in self-cured acrylic resin and permitted to set to make dentin blocks and then specimens were labeled for easy identification of each tooth under different treatment. Specimens were identified by letters (A-J) for knowing the tooth and digit (1-4) to the group. So different treatments were conducted on the same tooth. The dentin specimens were then stored in distilled water for 24 hours. 


\section{Baseline Micro-hardness tests}

The baseline microhardness estimations were taken at three different points on the dentin specimens. The indentations were made around 0.5 $\mathrm{mm}$ from the interface and $1 \mathrm{~mm}$ separated from each other ${ }^{(15)}$. Every estimation was completed utilizing a $100 \mathrm{~g}$ load for $15 \mathrm{~s}$, applied perpendicularly to the dentin surface. The diagonal lengths of indentations were measured by built-in scaled micrometer and estimations were changed over into Vicker's numbers. The values were averaged to produce one hardness value for each specimen. The microhardness estimations were performed utilizing a Vickers Microhardness Tester (Wilson miniaturized scale hardness analyzer, display Tukon 1102, Germany) with a Vickers diamond indenter and a 20X lens. Micro-hardness was acquired utilizing the accompanying equation: $\mathrm{HV}=1.854 \mathrm{P} /$ $\mathrm{d} 2$ Where, $\mathrm{HV}$ is Vickers hardness in $\mathrm{Kgf} / \mathrm{mm}^{2}, \mathrm{P}$ is the load in Kgf and d is the average length of the diagonals in $\mathrm{mm}$

\section{Preparation of grape seed extract}

The grape seed solution was prepared by measuring 15 grams of grape seed (GSE) powder (MegaNatural, Polyphenolics, Madera, California, USA) with sensitive balance. Then they were added to $100 \mathrm{ml}$ of ethyl alcohol anhydrous $\geq 99.5 \%$ solvent and dissolved carefully in water bath shaker at $1200 \mathrm{rpm}$ for $15 \mathrm{~min}$ to make a concentration of $15 \%$ GSE solution. The $\mathrm{pH}$ of the solution was adjusted by $\mathrm{pH}$ meter to make 7.2 utilizing few drops of $\mathrm{NaOH}$. The solution was filtered through filter paper no $6^{(16)}$

\section{Preparation of artificial carious lesion}

Lesions were produced by immersing the specimens into glass tubes containing $20 \mathrm{ml}$ of demineralizing solution $(50 \mathrm{mM}$ acetic acid derivation, $2.25 \mathrm{mM} \mathrm{CaCl} 22 \mathrm{H} 2 \mathrm{O}, 1.35 \mathrm{mM}$ $\mathrm{KH} 2 \mathrm{PO} 4 ; 130 \mathrm{~mm} \mathrm{KCl}$ for $\mathrm{pH}=5.0$ ), for 72 hours, at room temperature ${ }^{(17)}$.

\section{Remineralization protocols}

The demineralized dentin specimens were distributed among the four groups $(n=10)$ :

- Group 1: Demineralized specimens were left as a negative control group.

- Group 2: Demineralized specimens were immersed in $15 \%$ (w/v) GSE.

- Group 3: Demineralized specimens were immersed in $1000 \mathrm{ppm}$ aqueous solution of $\mathrm{NaF}$.

- Group 4: Demineralized specimens were immersed in artificial saliva (Na3PO4 $(3.90 \mathrm{mM}), \quad \mathrm{NaCl} \quad(4.29 \mathrm{mM}), \quad \mathrm{KCl}$ (17.98mM), $\quad \mathrm{CaCl} 2 \quad(1.10 \mathrm{mM}), \quad \mathrm{MgCl} 2$ $(0.08 \mathrm{mM}), \mathrm{H} 2 \mathrm{SO} 4(0.50 \mathrm{mM}), \mathrm{NaHCO} 3$ $(3.27 \mathrm{mM})$ and distilled water the $\mathrm{pH}$ adjusted to $7.2^{(16)}$.

\section{PH cycling}

The specimens were subjected to $\mathrm{pH}$-cycling (demineralization and remineralization) to simulate the cariogenic challenge ${ }^{(18)}$ in conjunction with the treatments according to the abovementioned groups except for the $1^{\text {st }}$ group. At first, the specimens were put in $50 \mathrm{ml}$ of treatment solution according to each group for 10 minutes, then in $50 \mathrm{ml}$ of demineralizing solution for 30 minutes lastly in $50 \mathrm{ml}$ of artificial saliva for 10 minutes. All the solutions were in constant agitation. These $\mathrm{pH}$ cycles/treatments were performed six times a day for eight days. Between the treatment and $\mathrm{pH}$ cycling, the specimens were washed thoroughly with distilled water. Between the daily cycling, the specimens were stored in the artificial saliva at $37^{\circ} \mathrm{C}^{(19)}$.

\section{Final surface Micro-hardness test}

Following the $\mathrm{pH}$-cycling/treatment process, the specimens were put in the ultrasonic cleaner for cleaning any outstanding debris on their surfaces. At that point, the micro- hardness estimation of 
the surface was taken and it was made between the initial hardness indentations. In this way, the final indentations were not in the same place as the initial ones and the markings were moved $100 \mu \mathrm{m}$ far from the past indentations through a digital microscope. The loads utilized were the same as the initial ones (300 grams for 10 seconds).

\section{Micromorphological examination}

Four specimens from the same tooth were chosen representing the different groups to be examined under the ESEM (Philips 505, Eindoven, Netherlands). The four recovered specimens were put in the ultrasonic cleaner for cleaning any outstanding deposits on their surfaces. Images were taken at $25 \mathrm{kV}$ and a magnification of $2000 \mathrm{X}$.

\section{Statistical Analysis}

Data analysis was performed by Kruskal-Wallis test followed by Dan Bonferroni Post hoc test to detect significance between groups. Statistical analysis was performed using SPSS version 22 software for Windows. P values $<0.05$ were considered to be statistically significant.

\section{RESULTS}

\section{Micro-hardness results}

Table 1 and figure 1 demonstrate the correlation between micro-hardness results (Mean \pm SD and level of significance) for all groups. They demonstrate that the GSE recorded the highest mean value followed by $\mathrm{NaF}$ then the artificial saliva. Meanwhile, the demineralized group recorded the lowest mean value. The difference between GSE and $\mathrm{NaF}$ groups was statistically non-significant. Also there was an insignificant difference between the group of artificial saliva and demineralized one. Meanwhile, there was a significant difference between both of them and the artificial saliva and the demineralized group respectively as indicated by Duncan's Post hoc tests $(\mathrm{p}<0.05)$.
TABLE (1) Comparison between micro-hardness results for all groups

\begin{tabular}{|l|c|c|c|}
\hline Group & $\begin{array}{c}\text { Mean } \\
\text { baseline } \\
\text { assessment }\end{array}$ & $\begin{array}{c}\text { Mean } \\
\text { Assessment } \\
\text { after treatment }\end{array}$ & P value \\
\hline Demineralized & $68.3 \pm 4.7$ & $20.2 \pm 2.7^{\mathrm{b}}$ & $0.005^{*}$ \\
\hline GSE & $67.0 \pm 4.7$ & $49.3 \pm 3.8^{\mathrm{a}}$ & $0.005^{*}$ \\
\hline $\mathrm{NaF}$ & $66.9 \pm 4.1$ & $49.2 \pm 5.0^{\mathrm{a}}$ & $0.005^{*}$ \\
\hline Artificial saliva & $67.5 \pm 3.6$ & $21.1 \pm 1.7^{\mathrm{b}}$ & $0.005^{*}$ \\
\hline P value & 0.834 & $<0.001^{*}$ & \\
\hline
\end{tabular}

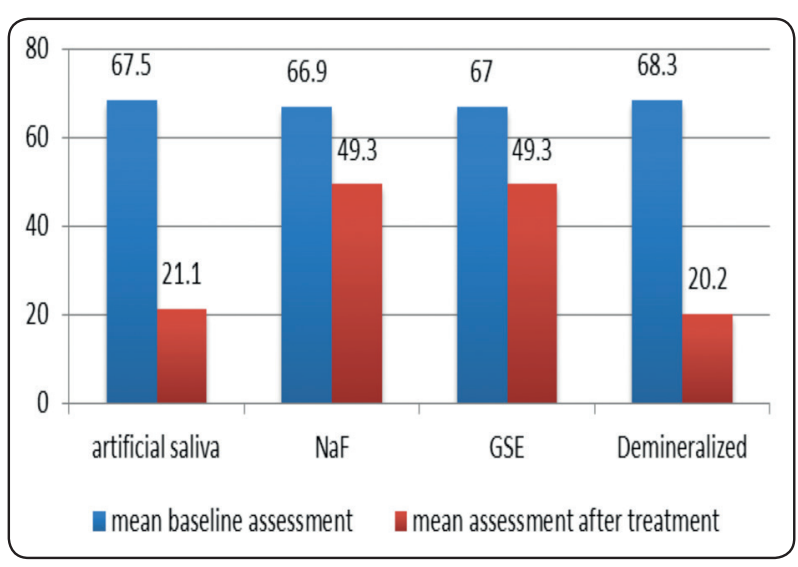

Fig. (1) Bar chart of micro-hardness means values for all groups

\section{Environmental Scanning electron microscope (ESEM) results}

The ESEM micrograph of the demineralized representative specimen, revealed widely opened dentinal tubules creating spongy like appearance. Some areas were completely demineralized and others were with partially demineralized peritubular dentin fig. (2). However, in the artificial saliva specimen, the micrograph showed opened dentinal tubules with different shapes, some had circular shape and others were with oval shape with small aggregates within the dentinal tubules fig. (3). The micrograph of the representative $\mathrm{NaF}$ and GSE specimens respectively fig. (4 \& 5), revealed almost complete obliteration of dentinal tubules and peritubular dentin leaving a smoother surface. 


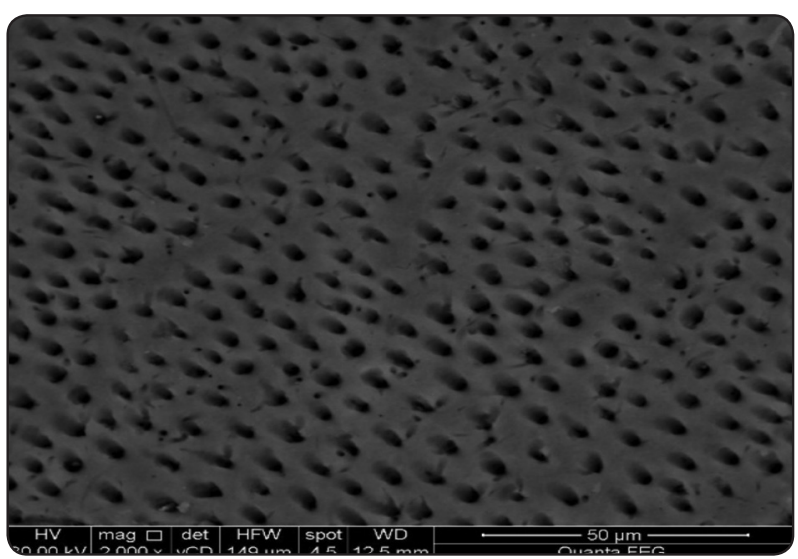

Fig. (2) ESEM showing demineralized dentin surface having opened dentinal tubules with different shapes, (circular or oval).

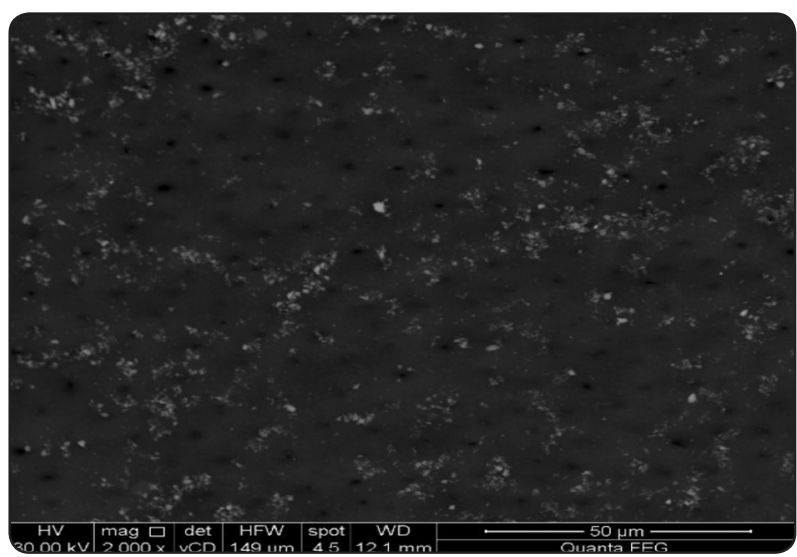

Fig. (4) ESEM showing dentin surface treated with $\mathrm{NaF}$ with almost complete obliteration of dentinal tubules and peritubular dentin.

\section{DISCUSSION}

By regulating the mineral balance favorably towards the remineralization, the caries lesion can be arrested or repaired through the regaining of some dissolved crystals, growth of surviving crystals and arrangement of new crystals ${ }^{(20)}$. Because of the littler extent of dentinal crystallites and presence of tubules filled with fluids, the dentin demonstrates great affinity towards the demineralization. It occurs at a critical $\mathrm{pH}$ higher than that for enamel (critical $\mathrm{pH} \approx 6.7)^{(21,22)}$.

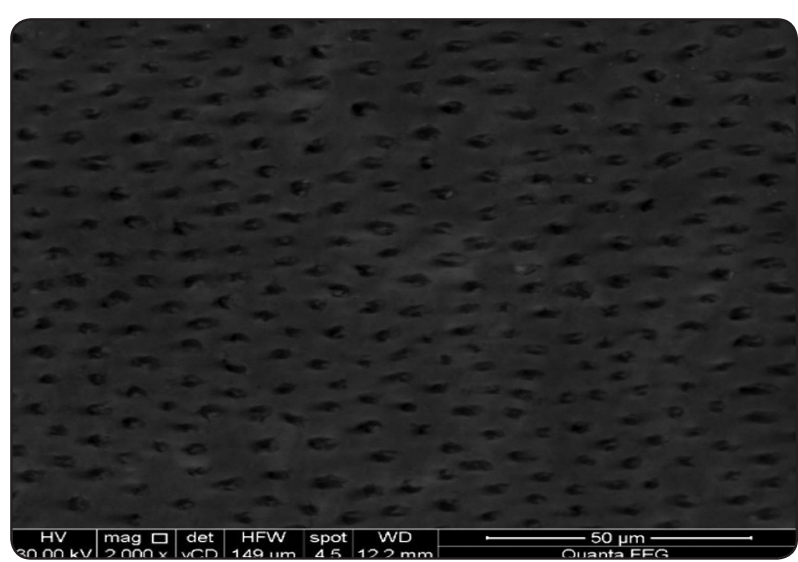

Fig. (3) ESEM showing dentin surface after storage in artificial saliva with small aggregates within the dentinal tubules.

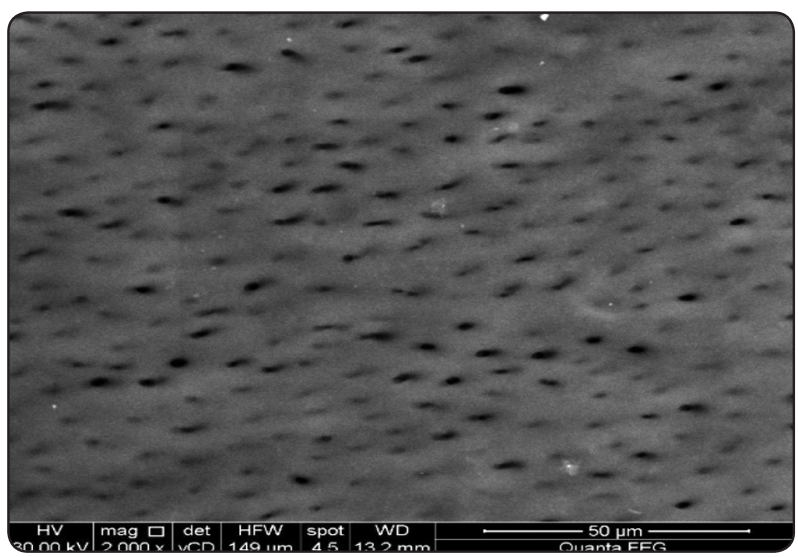

Fig. (5) ESEM showing dentin treated with GSE with almost complete obliteration of dentinal tubules and peritubular dentin.

In addition, after the mineral disintegration, exposed dentine organic matrices are additionally broken down by proteolytic enzymes, for example, bacterial derived collagenases and host derived matrix metalloproteinases. All these constraints drive the dentin deterioration to be an irreversible process and less well-suited to remineralization ${ }^{23}$, 24). Therefore, the management of dentine caries is much more challenging, highlighting an urgent need to seek novel and alternative strategies. Many agents were used for inducing remineralization for such depleted weak dentin. The fluoride anti-cariogenic 
effect can be credited to different reasons including enhanced calcium phosphate precipitation and fluoroapatite formation. Although caries preventive role of fluoride has been proved beyond any doubt, controlling this procedure of dentin deterioration utilizing fluoride alone seems questionable.

Collagen bio-alteration by exogenous collagen crosslinks, has been proposed to maintain, reestablish and enhance tissue biochemical and biomechanical properties ${ }^{(25)}$. In particular, these properties are desirable for prevention and restoration of dentin caries. Also they enhanced collagen stability against proteolytic degradation. The stabilized collagen can additionally inhibit demineralization and improve remineralization. Albeit different crosslinking agents, for example, glutaraldehyde, formaldehyde, carbodimide and epoxy compounds, have been utilized to initiate exogenous crosslinks, their invivo application has been generally constrained because of the cytotoxicity and instability after some time ${ }^{(26)}$, that is why other natural alternatives are recommended.

The current study utilized an artificial caries model, in which a demineralization time of three days was chosen as a longer period may deplete the collagen matrix of mineral and consequently hinder the remineralization ${ }^{27,28)}$. Following such protocol, a lesion depth of around $150 \mu \mathrm{m}$ with a micro hardness being similar to a natural carious lesion at the same depth was obtained ${ }^{(29)}$. Microhardness was utilized as an indirect method for detecting changes in mineral content that may reflect a decrease in mineral content ${ }^{(30-32)}$. Standardization of the obtained results were done by obtaining four specimens representing the different groups from the same tooth and so following the change in microhardness after the different treatments was definite. A natural remineralizing agent was represented by the artificial saliva and PA-rich GSE in contrast with fluoride were also utilized in the current study to stimulate dentin remineralization.
It had been proved that GSE successfully enhances the mechanical properties $\left.{ }^{33}, 34\right)$ and decreases the degradation rates of sound and caries affected dentine. ${ }^{(35)}$ It has the capacity to interact with and modify the dentine collagen. GSE may also play a role in diminishing collagen degradation by its inhibitory impact on proteases, for example intrinsic metalloproteinases ${ }^{(36)}$. Moreover, the protection of the collagen network may create a mechanical barrier to acid diffusion and mineral release and furthermore encourage mineral precipitation during the remineralization procedure. The GSEtreated group (fig. 5) delineated the formation of a well-defined outer layer when contrasted with the demineralized group (fig. 2). This layer might be the result of insoluble complex depositions formed by GSE when blended with the artificial saliva. In addition the GSE particles would link to the collagen, reinforcing the intertubular dentin to permit a more prominent remineralization process, as previously suggested for remineralization of artificial root caries ${ }^{(37)}$. Similar findings were found in the fluoride treated specimen as nearly obliterated dentinal tubules were found (fig. 4) which indicated evidence for dentin remineralization. This finding was supported by micro hardness values.

Straightforward precipitation of minerals into the demineralized dentin matrix in the artificial saliva group ( fig.3) might provide an increased mineral content however it may not really give an optimal interaction with the organic components of the dentin matrix ${ }^{(38)}$. This could be the explanation behind the diminished micro-hardness values after submersion of specimens in the artificial saliva despite the fact that there were little deposits inside the dentinal tubules. The present study highlights the critical positive remineralizing impact of GSE. However, no one from the used remineralizing agents regained the micro-hardness of the intact enamel. The null hypothesis was partially rejected as both fluoride and GSE produced the same remineralizing agent but the artificial saliva was 
inferior to them. Additional studies should be conducted to distinguish the active constituents of GSE and expand its impact on the tooth substrate and to find the optimal biocompatible remineralizing agent.

\section{CONCLUSION}

Within the conditions of the present study, grape seed extract is a promising nature driven remineralizing agent that can be compared with the gold standard fluoride. Artificial saliva alone cannot face the dentin demineralization.

\section{REFERENCES}

1. Marshall GW. Dentin: microstructure and characterization, Quint Inter; 24(9): 606-617, 1993.

2. Addy M, Pearce N. Etiologic, predisposing and environmental factors in dentin hypersensitivity, Archives of Oral Biology; 39: S33-S38, 1994.

3. Nyvad B, TenCate JM, Fejerskov O. Arrest of root surface caries in situ, J Dent Res; 76(12): 1845-1853, 1997.

4. Kawasaki K, Ruben J, Stokroos I, Takagi O, Arenda J. The remineralization of EDTA-treated human dentine, Caries Res;33(4):275-280, 1999.

5. Klont B, Ten Cate JM. Remineralization of bovine incisor root lesions in vitro. The role of the collagenous matrix, Caries Res;25(1): 39-45, 1991.

6. Daculsi G, Kerebel B, Lecabellec MT, Kerebel LM. Qualitative and quantitative data on arrested caries in dentin, Caries Res ;13(4): 190-202, 1979.

7. Qi YP, Li N, Niu LN, Primus CM, Ling JQ, Pashley DH, Tay FR. Remineralization of artificial dentinal caries lesions by biomimetically modified mineral trioxide aggregate, Acta Biomaterialia; 8, (2): 836-842, 2012.

8. Xu Z, Neoh KG, Lin CC, Kishen A. Biomimetic deposition of calcium phosphate minerals on the surface of partially demineralized dentine modified with phosphorylated chitosan, Journal of Biomedical Materials Research Part B-Applied Biomaterials; 98B(1): 150-159, 2011.

9. Linde A. Dentin matrix proteins: composition and possible functions in calcification, Anatomical Record; 224 (2): 154-166, 1989.
10. Lussi A, Linde A. Mineral induction in vivo by dentin proteins, Caries Res; 27(4): 241-248, 1993.

11. Ten Cate JM, Exterkate RA, Rempt HE. Intra-oral retention of fluoride by bovine enamel from amine fluoride toothpaste and $0.4 \%$ amine fluoride liquid application, J Dent Res;67: 491-495, 1988.

12. Chu JP, Li JY, Hao YQ, Zhou XD. Effect of compounds of Galla chinensis on remineralization of initial enamel carious lesions in vitro, J Dent; 35(38): 3-7,2007.

13. Wu CD. Grape products and oral health, J Nutr;139(9), 1818S-1823, 2009.

14. Akman S, Akman M, Eskitascioglu G, Belli S. Influence of several fiber-reinforced composite restoration techniques on cusp movement and fracture strength of molar teeth, Int Endodontic J ; 44:407-415, 2011.

15. Kirsten GA, Takahashi b MK, Rached RN, Giannini M, Souza EM. Microhardness of dentin underneath fluoridereleasing adhesive systems subjected to cariogenic challenge and fluoride therapy, J Dent; 48:460-468, 2010.

16. Castellan CS, Pereira PN, Grande RH, Bedran-Russo AK. Mechanical characterization of proanthocyanidindentin matrix interaction, Dent Mater; 26:968-973, 2010.

17. Rahiotis C, Vougiouklakis G. Effect of CPP-ACP agent on the demineralization and remineralization of dentine in vitro, J Dent; 35(8):695-698, 2007.

18. Xie Q, Bedran-Russo AK, Wu CD. In vitro remineralization effects of grape seed extract on artificial root caries, J Dent; 36:900-906, 2008.

19. Silva A, Gonçalves R, Borges A, Ana Russo. Effectiveness of plant-derived proanthocyanidins on demineralization on enamel and dentin under artificial cariogenic challenge, J Appl Oral Sci.;23(3):302-309, 2015.

20. Yanagisawa T, Miake Y. High-resolution electron microscopy of enamel-crystal demineralization and remineralization in carious lesions, J Electron Microsc (Tokyo) ; 52:605-613, 2003.

21. Ten Cate JM, Buijs MJ, Damen J. PH-cycling of enamel and dentin lesions in the presence of low concentrations of fluoride, Eur J Oral Sci; 103:362-367, 1995.

22. Hoppenbrouwers PM, Driessens FC, Borggreven JM. The mineral solubility of human tooth roots, Arch Oral Biol; 32:319-322, 1987.

23. Chaussain-Miller C, Fioretti F, Goldberg M, Menashi S. The role of matrix metalloproteinases (MMPs) in human caries, J Dent Res; 85:22-32, 2006. 
24. Kawasaki K, Featherstone JD. Effects of collagenase on root demineralization, J Dent Res; 76:588-595, 1997.

25. Bedran-Russo AK, Castellan CS, Shinohara MS, Hassan L, Antunes A. Characterization of biomodified dentin matrices for potential preventive and reparative therapies, Acta Biomater ;7:1735-1741, 2011.

26. Walter R, Miguez PA, Arnold RR, Pereira PN, Duarte WR, Yamauchi M. Effects of natural cross-linkers on the stability of dentin collagen and the inhibition of root caries in vitro, Caries Res; 42:263-268, 2008.

27. Heilman JR, Jordan TH, Warwick R, Wefel JS. Remineralization of root surfaces demineralized in solutions of differing fluoride levels, Caries Res;31(6): 423-428, 1997.

28. Clarkson BH, Hall DL, Heilman JR, Wefel JS. Effect of proteolytic enzymes on caries lesion formation in vitro, Journal of Oral Pathology \& Medicine; 15(8): 423-429, 1986.

29. Rehder-Neto FC, Menezes M, Chimello DT, Serra MC. Development of caries like lesions in human and bovine dentin compared to natural caries, Rev Odontol UNESP; 39(3):163-168, 2010.

30. Angker L, Nockolds C, Swain M V, Kilpatrick N. Correlating the mechanical properties to the mineral content of carious dentine - a comparative study using an ultra-micro indentation system (UMIS) and SEM-BSE signals, Archives of Oral Biology; 49(5): 369-378, 2004.
31. Arends J, Tenbosch JJ. Demineralization and remineralization evaluation techniques, J Dent Res; 71:924-928, 1992.

32. Ten Bosch JJ, Angmar-Mansson B. A review of quantitative methods for studies of mineral content of intraoral incipient caries lesions, J Dent Res ; 7(1):2-14, 1991.

33. Bedran-Russo AK, Pashley DH, Agee K, Drummond JL, Miescke KJ. Changes in stiffness of demineralized dentine following application of collagen crosslinkers, J Biomed Mater Res B Appl Biomater ;86B:330-334, 2008.

34. Bedran-Russo AK, Castellan CS, Shinohara MS, Hassan L, Antunes A. Characterization of biomodified dentin matrices for potential preventive and reparative therapies, Acta Biomater ; 7:1735-1741, 2011.

35. Macedo GV, Yamauchi M, Bedran-Russo AK. Effects of chemical cross-linkers on cariesaffected dentine bonding, J Dent Res; 88: 1096-1100, 2009.

36. Koide T, Daito M. Effects of various collagen crosslinking techniques on mechanical properties of collagen film, Dent Mater J; 16: 1-9, 1997.

37. Xie Q,Bedran-RussoAK, Wu CD.In vitro Remineralization effects of grape seed extract on artificial root caries, J Dent; 36: 900-906, 2008.

38. Bertassoni LE, Habelitz S, Marshall SJ, Marshall GW. Mechanical recovery of dentin following remineralization in vitro--an indentation study, J Biomech; 44(1): 176-181, 2011. 